\title{
Coarse woody habitat does not predict largemouth bass young of year mortality during the open water season
}

\begin{tabular}{|r|l|}
\hline Journal: & Canadian Journal of Fisheries and Aquatic Sciences \\
\hline Manuscript ID & cjfas-2018-0050.R2 \\
\hline Manuscript Type: & Article \\
\hline Date Submitted by the & 13 -Jul-2018 \\
\hline Complete List of Authors: & $\begin{array}{l}\text { Ziegler, Jacob; McGill University Department of Natural Resource } \\
\text { Sciences } \\
\text { Dassow, Colin; University of Notre Dame, Department of Biological } \\
\text { Sciences } \\
\text { Jones, Stuart; University of Notre Dame, Department of Biological } \\
\text { Sciences } \\
\text { Ross, Alexander; Cary Institute of Ecosystem Studies } \\
\text { Solomon, Christopher; Cary Institute of Ecosystem Studies }\end{array}$ \\
\hline Keyword: & $\begin{array}{l}\text { coarse woody habitat, littoral structure, lakeshore development, young } \\
\text { of year mortality, largemouth bass }\end{array}$ \\
\hline Is the invited manuscript for \\
consideration in a Special \\
Issue?:
\end{tabular}$\quad$\begin{tabular}{l} 
Not applicable (regular submission) \\
\hline
\end{tabular}


1 Coarse woody habitat does not predict largemouth bass young of year mortality during the 2 open-water season

3 Jacob P. Ziegler ${ }^{1}$, Colin Dassow ${ }^{2}$, Stuart E. Jones ${ }^{2}$, Alexander J. Ross ${ }^{3}$, Christopher T. Solomon ${ }^{3}$

4 1. Natural Resource Sciences, McGill University, Montreal, QC, jacob.ziegler@mail.mcgill.ca

5 2. Biological Sciences, University of Notre Dame, South Bend, IN

6 3. Cary Institute of Ecosystem Studies, Millbrook, NY 


\section{Abstract}

8 Littoral structure is often assumed to provide refuge to young of year (YOY) freshwater fish

9 species but empirical in situ tests of this relationship are lacking. We estimated mortality rates of

10 young of year (YOY) largemouth bass (Micropterus salmoides) over the open-water season in 13

11 lakes in northern Wisconsin and Michigan, using repeated snorkel surveys. Our goal was to test

12 the hypothesis that mortality rate is negatively related to the abundance of littoral coarse woody

13 habitat, which ranged from 3-1500 pieces of wood per $\mathrm{km}$ of shoreline in these lakes.

14 Instantaneous mortality rates were well-constrained and ranged from 0.04 to 0.19 among the 13

15 lakes. Mortality was not related to coarse woody habitat abundance. Our results suggest that the

16 relationship between coarse woody habitat and YOY mortality might not be as strong or

17 universal as is often assumed. 


\section{Introduction}

Young of year (YOY) mortality is an important determinant of population dynamics, and managing to minimize YOY mortality can increase productivity and resilience of fish

21 populations. Literature reviews of experiments focused on mortality in stage-structured

22 populations provide empirical evidence that changes in YOY mortality have significant and often

23 counterintuitive effects on population abundance (Zipkin et al. 2009; Schröder et al. 2014). In a

24 theoretical study, Carpenter and Brock (2004) illustrated that reducing YOY mortality in lakes

25 had the combined effect of increasing the level of harvest a fish stock can withstand before

26 collapsing and decreasing the benefits anglers receive from overfishing. Additional theoretical

27 studies have demonstrated that freshwater fish species with higher YOY mortality require larger

28 population sizes to persist (Velez-Espino and Koops 2012) and population growth rates for most

29 freshwater fish species are more sensitive to YOY mortality than adult mortality (Van der Lee

30 and Koops 2015). Population level outcomes of YOY mortality can affect community level

31 outcomes through Allee, emergent facilitation, predator exclusion, and cultivation effects

32 (Walters and Kitchell 2001; Persson and de Roos 2013). However, YOY mortality estimates of

33 freshwater fish species are rare and those that span environmental gradients, which build

34 intuition of how YOY mortality might vary with environmental change, do not exist.

35 Much of the research to date on controls of early-life mortality and recruitment of

36 freshwater fish species has ignored mortality during the open-water season, instead focusing on

37 body size and the advantages it confers for overwinter survival. Early studies investigating

38 controls of YOY mortality were conducted in systems without top predators (Ludsin and

39 DeVries 1997; Post et al. 1999; Pine et al. 2000) or only considered overwinter mortality (Post

40 and Evans 1989; Miranda and Hubbard 1994a; Miranda and Hubbard 1994b). These studies 
41 provided evidence that YOY with larger body sizes had lower overwinter mortality, likely due to

42 an increased foraging ability and higher fat stores (although see Rogers and Allen 2009 who did

43 not detect an effect of size-dependent overwinter mortality). However, body size is largely

44 determined by hatch date and growth rates (Miller et al. 1988), variables that are difficult for

45 fisheries managers to control.

46 Open-water season YOY mortality has been largely ignored in studies but there is some

47 evidence that it is a determinant of recruitment success in largemouth bass. Like research on

48 YOY mortality in general, much of the focus of largemouth bass YOY mortality has been on the

49 potential for increased body size to decrease overwinter mortality (Miranda and Hubbard 1994a;

50 Miranda and Hubbard 1994b; Olson 1996; Garvey et al. 1998; Miller and Storck 2011; Miranda

51 and Muncy 2011; Pine et al. 2000). During the open-water season however, Rogers and Allen

52 (2009) found no effect of body size on largemouth bass YOY mortality. While Rogers and Allen

53 (2009) were unable to compare the relative importance of overwinter mortality to open-water

54 season mortality, Post et al. (1998) found that the open-water season represented a more extreme

55 bottleneck for largemouth bass YOY survival than overwinter survival. In addition, Post et al.

56 (1998) found that estimates of YOY predation during the open-water season explained 98\% of

57 the variation in observed initial YOY densities, suggesting that nearly all YOY mortality during

58 the open water season was due to predation.

Coarse woody habitat is generally assumed to reduce YOY predation and mortality rates

60 in temperate lakes by providing refuge from predators, but empirical tests of this hypothesis have

61 yielded mixed results. Fish species are frequently found in littoral structure like coarse woody

62 habitat and submerged macrophytes during their early-life stages (Hall and Werner 1977; Wallus

63 and Simon 2008; Lewin et al. 2004), which has led to the assumption that this habitat is used as 
64 refuge (MacRae and Jackson 2001; Wallus and Simon 2008; Roth et al. 2007; Wallus and Simon

65 2008; Biggs et al. 2009; Ziegler et al. 2017). However, DeBoom and Wahl (2013) found no

66 effect of coarse woody habitat abundance on predation of YOY of two species in mesocosm

67 experiments and Klecka and Boukal (2014) found that littoral structure can be used as an ambush

68 site by some predators. Alternatively, in an overwinter pond experiment Miranda and Hubbard

69 (1994a) found that coarse woody habitat provided refuge from mortality for the smallest of four

70 size classes of YOY largemouth bass, indicating an interaction between starvation and predation

71 vulnerability, and Sass et al. (2006a) found that yellow perch experienced a recruitment failure

72 after a whole lake removal of coarse woody habitat. They attributed the recruitment failure to

73 increased predation pressure on YOY yellow perch and lack of spawning substrate.

74 The assumption that littoral structure is refuge for YOY has led aquatic and fisheries

75 researchers to suspect that a threshold of coarse woody habitat exists, below which fish

76 populations experience adverse effects from increased YOY mortality (Carpenter and Brock

77 2004; Liu et al. 2007). Coarse woody habitat is sensitive to human development and often

78 completely absent when there are more than 7 houses per kilometer of shoreline (Marburg et al.

79 2006; Liu et al. 2007). The assumption that YOY mortality is affected by coarse woody habitat

80 and in turn by housing development has been included in many studies of littoral species (Brock

81 and Carpenter 2007; Biggs et al. 2009; Ziegler et al. 2017). However, there have been no

82 comparisons of YOY mortality among lakes across gradients of coarse woody habitat density. In

83 situ mortality estimates can provide insights into factors regulating recruitment success to help

84 guide sustainable development and fisheries management.

85 In this study, we tested for a relationship between littoral habitat structure and YOY

86 mortality during the open-water season by estimating largemouth bass YOY mortality rates in 13 
87 lakes that varied in coarse woody habitat density. Based on the prevalent hypothesis that coarse

88 woody habitat reduces predation pressure on YOY, we predicted that coarse woody habitat

89 would be negatively correlated to YOY mortality.

\section{$90 \quad$ Methods}

$91 \quad$ Study sites

92 We selected 13 small lakes in northern Wisconsin and the Upper Peninsula of Michigan

93 USA that had largemouth bass as the dominant piscivore, and which spanned previously

94 documented coarse woody habitat gradients (Table I). Development in this lake-rich forested

95 region has been rapid since the 1940s and is often concentrated around lakes (Carpenter et al.

96 2007). As a result, there are various degrees of lakeshore development in the region resulting in a

97 range of coarse woody habitat in lakes (see videos in supplemental information for what the

98 littoral zone of a lake with high coarse wood habitat density looks like in this region). Littoral

99 coarse woody habitat has been observed to vary from 0 to 965 pieces of wood per kilometer of

100 shoreline in this region (Christensen et al. 1996; Marburg et al. 2006). Our study lakes extended

101 this gradient to $3-1520$ pieces of wood per kilometer of shoreline (Table I).

102 Young of year mortality

103 We estimated YOY largemouth bass instantaneous mortality rates in each lake using the

104 decline in YOY relative abundance over the open-water season, following the methods of Essig 105 and Cole (1986) and Miranda and Hubbard (1994b). We estimated relative abundance on at least 1064 occasions in each lake, at approximately biweekly intervals from the beginning of June (just 107 after swim-up) until late August or early September of 2016 or 2017 (Table I). In both years

108 largemouth bass successfully produced cohorts, and when we returned in 2017 to lakes that had 109 been sampled in 2016 we did not observe major differences in bass recruitment between the two 
110 years. There were no notable events that would cause recruitment failures during our study

111 period (e.g. anoxia, algal blooms, or large decreases in water level or temperature). We used line-

112 transect snorkel surveys similar to Weidel et al. (2007) and Chamberland et al. (2013) to quantify

113 relative abundance. We determined through a pilot study in our lakes that electrofishing was not

114 effective at capturing YOY in the spring and early summer, while snorkel surveys allowed for

115 consistent quantification of YOY throughout their first open-water season and did not affect

116 YOY mortality unlike electrofishing and rotenone sampling (Chamberland et al. 2013).

117 Numerous studies have shown strong correlations ( $\mathrm{R}^{2}$ between 0.88 and 0.99$)$ between snorkel

118 survey counts and absolute abundances of littoral fish in both lakes and rivers (Mullner et al.

119 1998; Pink et al. 2007; Weidel et al. 2007; Chamberland et al. 2013) and Brind'Amour and

120 Boisclair (2004) found no difference between relative abundance estimates of lake littoral fish

121 when measured using snorkel surveys or beach seines.

122 Relative abundance estimates are an accurate measure of the decline in YOY if

123 detectability of YOY does not change within a lake over time. We controlled for and estimated

124 habitat related detectability in our sampling and we tested for potential biases in YOY detection

125 due to changes in water clarity. We always returned to the same sites and transects in each lake

126 to maintain the same littoral structure density on transects over the sampling period. Within lakes

127 we tested for an effect of coarse woody habitat on YOY detection probability using well-

128 developed theory from species occupancy modeling (MacKenzie et al. 2002). We calculated the

129 site level detection probability of YOY using logistic regression with 8 observations of YOY

130 presence or absence on transects at each of the 6 sites per lake and sampling day (see

131 Mollenhauer et al. 2018 for spatial re-sampling method of MacKenzie et al. 2002). Transect level

132 coarse woody habitat density was included as a predictor of site level variation in YOY detection 
133 probability. We compared logistic regression models that allowed the effect of coarse woody

134 habitat on YOY detection probability to remain constant or vary among sites and over time using

135 AICc. Similar to Toft et al. (2007) we measured water clarity at the time of sampling as a

136 covariate of visual detectability to determine if it changed over time. We measured water clarity

137 as horizontal Secchi distance, vertical Secchi depth, and percent cloud cover. We also looked for

138 changes in behavioural responses of YOY largemouth bass to divers over the study period and

139 we considered potential biases in our results related to increased fish length over time (see

140 supplemental information).

141 On each lake visit we conducted snorkel surveys at six littoral sites located at the north,

142 northeast, east, south, southwest, and west edges of the lake. At each site we sampled eight $10 \mathrm{~m}$

143 transects that extended perpendicular from shore because YOY largemouth bass are littoral

144 (Wallus and Simon 2008) and transect orientation should be perpendicular, rather than parallel,

145 to the density gradient of the object of interest (Buckland et al. 1993). We marked the end of

146 transects on the shoreline with flagging tape and the start from a boat using a buoy and a range

147 finder, being careful never to disturb transects. Two divers entered the water approximately $30 \mathrm{~m}$

148 from transects, approached each transect slowly and calmly, swam in parallel at a constant rate

149 of $10 \mathrm{~m}$ per minute, and recorded on underwater tablets the number of YOY largemouth bass

150 within their line of sight. It is common methodology to estimate school size when there are more

151 fish than divers can count; we improved on this methodology by using video analysis to provide

152 reproducible, unbiased, and more accurate counts of YOY when there were more than 5 YOY

153 present on a transect (Buckland et al. 1993). Each underwater transect was filmed using a GoPro

154 Hero 4 (GoPro Inc., San Mateo, California) and in instances where more than 5 YOY were

155 encountered on a transect all YOY were captured on video and then video frames were used to 
156 count individuals using the cell counter plugin on ImageJ 1.x (Schneider et al. 2012; De Vos

157 2010). While using video counts might change the detection probability of YOY compared to

158 only using snorkel counts, any bias introduced here is likely to be much smaller than simply

159 estimating school size as is standard practice in snorkel surveys. Videos typically had good

160 visibility allowing for easy counting of YOY present in video frames.

161 We conducted additional line-transect samples in pelagic habitat in each lake to confirm

162 the absence of significant ontogenetic habitat shifts that could have biased the mortality rates that

163 we estimated from our littoral sampling. We sampled at three sites per visit just offshore of

164 littoral sites. The total amount of pelagic sampling varied per lake but was conducted at least

165 twice (once early in the season and once later in the season) and on average three times per lake

166 over the sampling period. We set $40 \mathrm{~m}$ pelagic transects parallel to shore at $30 \mathrm{~m}$ and $40 \mathrm{~m}$ from

167 shore, using a thin white nylon line set at half the thermocline depth. If the thermocline depth

168 was greater than two meters scuba divers swam along the transect line at a speed of $10 \mathrm{~m}$ per

169 minute, and recorded YOY largemouth bass in the same manner as littoral transects. If the

170 thermocline depth was less than two meters and divers could see past two meters in the water

171 column (judged by vertical Secchi depth) the pelagic transects were snorkeled in the same

172 manner as littoral transects.

\section{Littoral structure}

174 We determined the density of coarse woody habitat, the structural complexity of coarse 175 woody habitat, and the density of macrophytes, another form of littoral structure, in each of our 176 study lakes. Coarse woody habitat density was previously estimated for eight of our study lakes

177 by Marburg et al. (2006) and we estimated coarse woody habitat in our other five lakes following

178 their methods. We also estimated coarse woody habitat density in all thirteen lakes by 
179 quanitfying the number of pieces of wood present on our littoral transects from video footage.

180 Our video-derived estimates of coarse woody habtiat density were strongly correlated with the

181 estimates from Marburg et al. (2006) $(r=0.92, p<0.01, n=6)$, so we present only the latter here.

182 We used video footage to estimate the mean branchiness of woody habitat (following the

183 methods of Marburg et al. 2006) and percent macrophyte cover.

\section{$184 \quad$ Statistical analyses}

185 The expected size of a population $X$ at time $t$ undergoing a random death process is given

186 by a negative exponential model with initial abundance $X_{0}$ and mortality rate $z$ (Bailey 1990),

187 with errors that might be distributed with Poisson or negative binomial distributions (Bolker 188 2008):

191 Or

194 We estimated the initial abundance $\left(X_{0}\right)$, mortality rate $(z)$, and the dispersion parameter $(k$, 195 Equation 2 only) along with their 95\% confidence intervals for all 13 lakes by fitting our count 196 data over time to Equation 1 and 2 using maximum likelihood (Table I and Fig. 1). We compared

197 fitted models relative to each other with small-sample size corrected Akaike's Information 198 Criterion (AICc). All statistical analyses were conducted in R using packages MASS and 199 AICcmodavg (Venables and Ripley 2002; R Core Team 2017; Mazerolle 2017).

200 To test for potential effects of coarse woody habitat density, coarse woody habitat 201 complexity, and the density of macrophytes on YOY mortality we used ordinary least squares 
202 regression and weighted least squares regression with mortality estimates ( $z$ in Equation 1 and 2)

203 as the dependent variable and coarse woody habitat and littoral structure as the predictor

204 variables (Fig. 3). In weighted least squares regression we weighted mortality estimates by the

205 inverse of their squared standard errors (Chatterjee and Hadi 2015). For simplicity, all results

206 presented in figures are from models that had a single predictor of YOY mortality, however, we

207 tested all predictor variables individually and in combination with each other, including

208 interactions (Table SII). When an estimated dependent variable (EDV) is used in regression it

209 can violate assumptions of heteroscedasticity due to variation in the EDV's $95 \%$ confidence

210 intervals (Hanushek 1974; Williams and Lewis 2008). Two approaches are frequently used to

211 deal with EDV regression: ordinary least squares and weighted least squares (Williams and

212 Lewis 2008; Chatterjee and Hadi 2015). Ordinary least squares regression (OLS) allows some of

213 the error in the regression model to be unexplained by predictor variables but does not account

214 for known variation in measurement error when estimating regression parameters and standard

215 errors. Weighted least squares regression (WLS) does not allow unexplained variation from

216 predictor variables (i.e. it assumes all of the error in the regression model is due to measurement

217 error and $\mathrm{R}^{2}$ would be 1 if the EDV were directly observable) but accounts for measurement

218 error in the EDV when fitting regression parameters and standard errors. Therefore, we report

219 both OLS and WLS results as recommended by Williams and Lewis (2008). In all instances, we

220 plotted the $95 \%$ confidence intervals from the WLS regression fits as they accounted for

221 uncertainty in mortality parameter estimates.

222 When testing for an effect of littoral structural complexity on YOY mortality we could

223 not include coarse woody habitat density and mean coarse woody habitat branchiness in the same

224 model because they were positively correlated $(\mathrm{r}=0.84 \mathrm{p}<0.01)$. Therefore, to characterize total 
225 littoral structure we ran a principal component analysis, which explained $94 \%$ of the variation in

226 coarse woody density, coarse woody branchiness, and macrophyte cover in two principal

227 components (PC1 and PC2 in Table II). We then used the principal components, which

228 corresponded to coarse woody habitat complexity (PC1) and macrophyte cover (PC2), as

229 predictor variables of YOY mortality following the same methods as above.

230 Our hypothesis assumes that predation pressure is a strong control of YOY mortality in 231 our lakes, as has been demonstrated in previous studies (Anderson 1988; Duarte and Alcaraz

232 1989; Post and Evans 1989; Ludsin and DeVries 1997; Post et al. 1998; Post et al. 1999; Post

233 and Parkinson 2001). We used historical data on predator densities in a subset of our lakes to

234 corroborate this assumption (see Supplemental Information Section I).

\section{Results}

236 Young of year mortality

237 Young of the year counts significantly and exponentially declined over the study period 238 in all lakes (Fig. 1). On average, we sampled $4.6 \mathrm{~km}$ of transect per lake and observed 4,400

239 YOY per lake over the study period. For all lakes, a negative exponential-negative binomial 240 model fit our observed count data better than a negative exponential-Poisson model (in all

241 instances $\triangle \mathrm{AIC}>100)$. Young of the year largemouth bass mortality estimates in the thirteen

242 lakes ranged from 0.04 to 0.19 with a mean of 0.11 and a standard deviation of 0.04 , and had

243 reasonably well-constrained confidence intervals (Table I).

244 Our ability to detect YOY was, for the most part, unrelated to coarse woody habitat

245 density and water clarity did not significantly vary over time. There was no significant effect of

246 CWH on YOY detection probability in 11 of our 13 lakes (Fig. 2). In one lake, the effect of

247 coarse woody habitat significantly varied by site and had a significant positive effect on 
248 detection probability in two sites (West Long in Fig. 2, $\triangle$ AICc from a model with constant site

249 effect $>2$ ). Coarse woody habitat had a significant negative effect on YOY detection probability

250 in only one lake but this lake had the lowest coarse woody habitat density of all lakes (Fig 2,

251 Johnson Lake). Therefore, it is likely that the decline in detection probability with coarse woody

252 habitat observed in Johnson Lake was ecologically driven rather than determined by a diver's

253 reduced ability to see YOY when coarse woody habitat was present. In all lakes, the effect of

254 coarse woody habitat on site level YOY detection probability did not vary over time as our best

255 model predicting site detection probability included a constant coarse woody habitat effect over

256 time for all lakes (Fig. 2, $\triangle \mathrm{AICc}>50$ compared to model with coarse woody habitat effect

257 varying by lake, site, and time). Water clarity in each lake at the time of sampling did not

258 significantly change over the study period when measured as horizontal Secchi distance (p

259 values for the day of year effect in a regression model with lake as a blocking factor were all

260 greater than 0.05 for all lakes) and vertical Secchi depth (all $p>0.05$ ). Cloud cover at the time

261 of sampling did not significantly change over the study period (all $p>0.05$ ).

262 The declines in YOY counts were not due to ontogenetic shifts from littoral to pelagic

263 habitats. We did not detect YOY largemouth bass on pelagic transects in 9 of our 13 lakes,

264 despite an average $740 \mathrm{~m}$ of pelagic transect line sampling per lake over the study period. In two

265 lakes, young of the year were present on pelagic transects only where those transects were as

266 shallow or more shallow than the littoral transects (i.e. not representative of pelagic habitat but

267 rather additional littoral habitat). In the remaining two lakes, a negative exponential, negative

268 binomial model described the decline in pelagic YOY counts over the open-water season and the

269 pelagic mortality estimates did not significantly differ from littoral mortality estimates (mortality

270 parameter estimate and $95 \%$ CI for pelagic YOY counts: $\mathrm{z}=0.05 \pm 0.02$ and $\mathrm{z}=0.07 \pm 0.03$, 
271 mortality parameter estimate and 95\% CI for littoral YOY counts: $\mathrm{z}=0.05 \pm 0.02$ and $\mathrm{z}=0.08 \pm$

2720.02 , respectively). Therefore, it is unlikely that movement of YOY to pelagic habitat could

273 account for the significant decline in littoral YOY counts in our lakes as pelagic YOY were

274 either not present or, when they were present, declined at the same rate in both habitats.

\section{Littoral structure and young of year mortality}

In our 13 lakes, which spanned a large coarse woody habitat gradient ( $3-1500$ pieces of

277 wood per km of shoreline), YOY mortality was unrelated to coarse woody habitat, coarse woody

278 habitat complexity, and macrophyte cover (Fig. 3 and 4, Table SI). Mortality was not

279 significantly related to coarse woody habitat in WLS or OLS models (Fig. 3A, Table SI). Our

280 data constrained the effect of coarse woody habitat on YOY mortality to near zero (Fig. 4).

281 Coarse woody structural complexity and macrophyte cover (Table II PC1) were also poor

282 predictors of YOY mortality during the open-water season and were not significant in any WLS

283 or OLS models (Fig. 3B and C, Table SI).

\section{Discussion}

285 Our results are, to our knowledge, the first to compare in situ YOY mortality along an 286 environmental gradient in lakes, and suggest that the relationship between coarse woody habitat 287 and YOY mortality might not be as strong or universal as is often assumed. Although our results 288 are limited in sample size and only consider one freshwater fish species they suggest that littoral 289 structure variations alone may not lead to decreased YOY mortality as is often assumed in the 290 literature (MacRae and Jackson 2001; Carpenter and Brock 2004; Wallus and Simon 2008;

291 Brock and Carpenter 2007; Roth et al. 2007; Wallus and Simon 2008; Biggs et al. 2009; Allen et 292 al. 2011; Ziegler et al. 2017). Our results also advance our understanding of early-life mortality 293 of largemouth bass over the open-water season and provide an example that can be used to better 
294 understand early-life mortality and its determinants in other species through well-constrained 295 estimates of YOY mortality.

296 Our estimates of open-water season YOY mortality are comparable to the few estimates

297 that exist for largemouth bass and suggest that open-water season mortality is greater than 298 overwinter mortality. There are only three published estimates of YOY largemouth bass open299 water season mortality that we are aware of (Miranda and Hubbard 1994b; Shirley and Andrews 300 1977; Rogers and Allen 2009). Only two studies provided instantaneous mortality estimates: 301 Shirley and Andrews (1977) provided one without an error estimate $(\mathrm{z}=0.0028)$ making it 302 dificult to compare with our estimates, while Rogers and Allen (2009) had 6 estimates with a 303 range of 0.019 to 0.12 . Our instantaneous mortality rates were well-constrained and ranged from $3040.04 \pm 0.02$ to $0.19 \pm 0.09$ among 13 lakes, which is similar to the range observed by Rogers and 305 Allen (2009). Rogers and Allen (2009) found that open-water season mortality alone was as high 306 or higher than overwinter mortality. Our range in estimates of open-water season mortality are 307 higher than those reported for largemouth bass overwinter mortality (range in estimates from 308 Garvey et al. 1998 and Miranda and Hubbard $1994 a=0.00008$ to 0.04 ). Despite the focus in the 309 literature on overwinter mortality and its implications for recruitment success, our results suggest 310 that open-water season mortality should be as great or greater a concern for recruitment success 311 than overwinter mortality in largemouth bass.

312 High open-water season YOY mortality in largemouth bass could have a compensatory

313 effect at the population level, especially when cannibalism is high, by reducing density-

314 dependent competition of YOY for resources. A Ricker stock-recruitment relationship predicts

315 that recruitment should decline at higher adult population densities if there is cannibalism by

316 adults (Ricker 1954). Despite cannibalism accounting for the majority of largemouth bass YOY 
317 mortality in Post et al. (1998) they found no relationship between adult density and recruitment

318 success. One explanation for this is that self-thinning through cannibalism may remove density

319 dependent mortality that YOY might otherwise experience and compensate for increased

320 predation pressure at higher adult densities. Based on our range of mortality rates $(0.04 \pm 0.02$ to

$3210.19 \pm 0.09$ ) and study duration, largemouth bass populations can lose between $68 \%$ and $99 \%$ of

322 their YOY populations over the open-water season. These large declines in abundance, most

323 likely caused by predation pressure (see Supplemental Information Section I), would reduce

324 competition among the remaining YOY for resources and improve their chance for successful

325 recruitment to older life stages.

326 While littoral structure may not serve as refuge for YOY largemouth bass, researchers

327 have hypothesized it is refuge to other freshwater species. For example, YOY rainbow trout

328 (Tabor and Wurtsbaugh 1991), yellow perch (Eklöv 1997), and walleye (Pratt and Fox 2001)

329 have been assumed to use littoral structure to reduce predation pressure. However, few empirical 330 test have provided evidence for this (Savino and Stein 1982; Tabor and Wurtsbaugh 1991; Sass

331 et al. 2006b). Behavourial differences in boldness of species may explain why largemouth bass

332 do not receive refuge from littoral structure but species like bluegill, that adapt their behavour to

333 predators, do (Savino and Stein 1982; Turner and Mittelbach 1990). There is a known tradeoff of

334 boldness in largemouth bass, bold juveniles experience increased predation mortality but bold

335 adults expereince higher fitness and pass on their heritable behavioural trates (Ballew et al.

336 2017). Other known predictors of recruiment success among species are climate change, lake

337 morphometry, overharvesting, and spawning substrate (Walters and Kitchell 2001; Nash et al.

338 2001; Hansen et al. 2015) but without well controlled studies estimating YOY mortality, the

339 relative importance of these predictors and their interactions remains unclear. 
Our analysis demonstrates how well-constrained mortality estimates can advance our

341 understanding of determinants of freshwater fish early-life mortality and recruitment success.

342 Our approach, while time intensive (65 days of snorkel surveys for 13 mortality estimates) might

343 be useful in similar studies of littoral species in small lakes. Our approach might also be

344 powerfully combined with large-scale experiments; for instance, one could manipulate wood

345 levels and measure YOY mortality response in a whole-lake, before-after control-impact design.

346 Other promising approaches for understanding determinants of YOY mortality in multiple

347 systems include using marked stocked YOY (Shirley and Andrews 1977), standardized long

348 term monitoring of YOY over the open-water season among multiple lakes (Post et al. 1998),

349 and metaanalyses.

350 Fisheries management focused on maintaining productive fish stocks requires knowledge

351 of critical variables like YOY mortality and how they might change with habitat modifications

352 like removal or addition of littoral structure. Thresholds of critical variables that can lead to

353 undesirable changes in social-ecological systems are a key concept in resilience thinking (Folke

354 2016). Understanding where these critical thresholds lie and avoiding trajectories that cross them

355 is the role of responsible natural resource management. The concept of a safe operating space

356 bounded by critical thresholds has recently been applied to fisheries management and illustrates

357 the necessity of understanding which critical variables a manger can control and how best to

358 allocate effort in managing them (Carpenter et al. 2017). For example, federal fisheries

359 management in Canada has shifted from protecting fish habitat to protecting fish productivity,

360 which requires a better understanding of the effects that habitat alterations have on critical

361 variables for fish productivity like YOY mortality (Rice et al. 2015). Our results provide useful

362 but rare estimates of in situ YOY mortality along a littoral structure gradient and suggest that 
363 littoral structure may not be as strong or universal a control on open-water season YOY mortality

364 as is often assumed.

365 Acknowledgements

366 We thank the University of Notre Dame Environmental Research Center (UNDERC) for

367 hosting our research. We are exceptionally grateful to the Northern Temperate Lakes Long-Term

368 Ecological Research Database for data used in this manuscript and to two reviewers whose

369 comments greatly improved this manuscript. This work was supported by the Natural Sciences

370 and Engineering Research Council of Canada Graduate Scholarships Doctoral program under

371 grant number 475586-2015 to J. P. Ziegler, the National Science Foundation under grant number

3721716066 to C.T. Solomon and S.E. Jones, and the 2017 McNALMS and MLSA Lake Research

373 Grants Program.

374 


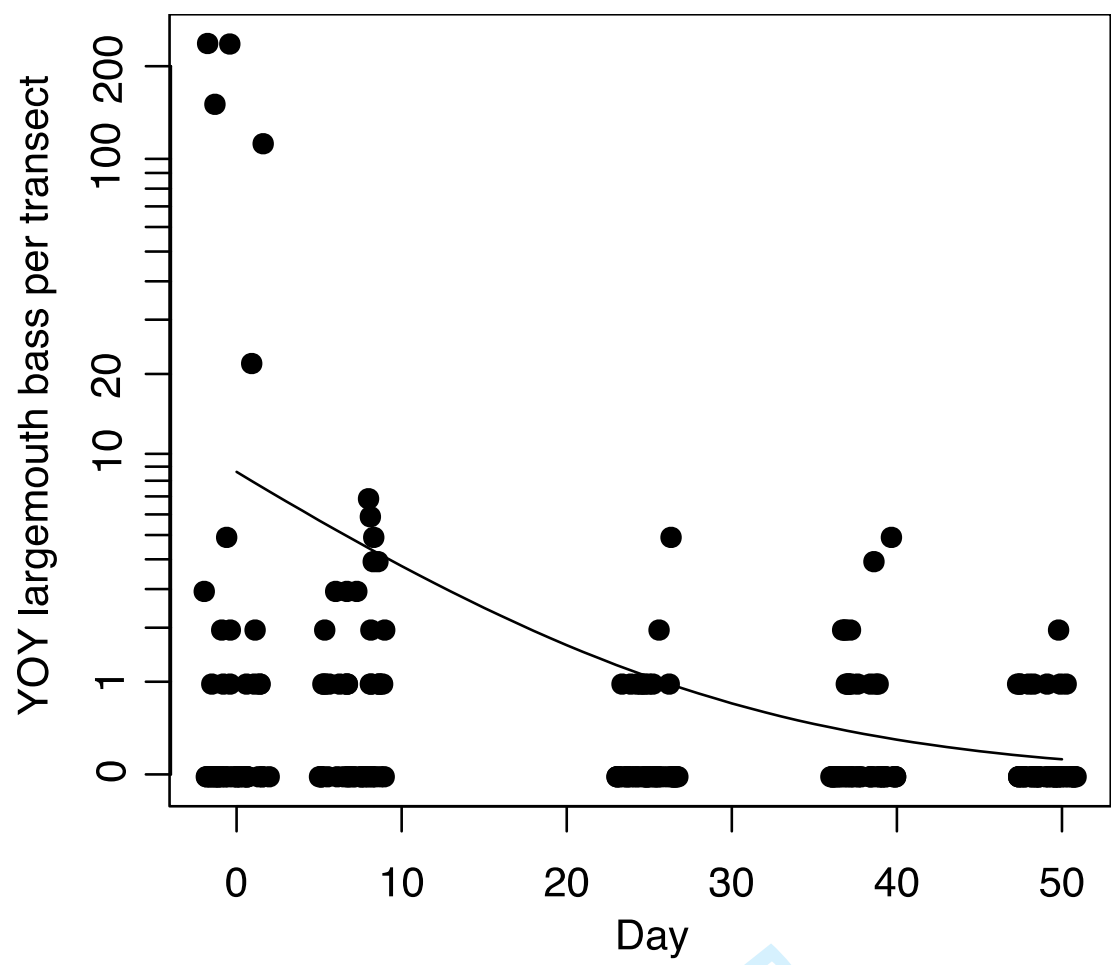

Figure 1. An example of young of year (YOY) largemouth bass counts per $10 \mathrm{~m}$ transect line over study period for a single lake (see SI Fig. S2 for plots from all lakes). Individual points represent total number of YOY present on a $10 \mathrm{~m}$ transect line and are jittered to prevent over plotting (sampling days were $0,7,25,38$, and 49). The solid line shows the fit of the model used to estimate YOY mortality (a negative exponential model with negative binomial errors). Note that the y-axis is in logarithmic scale. 


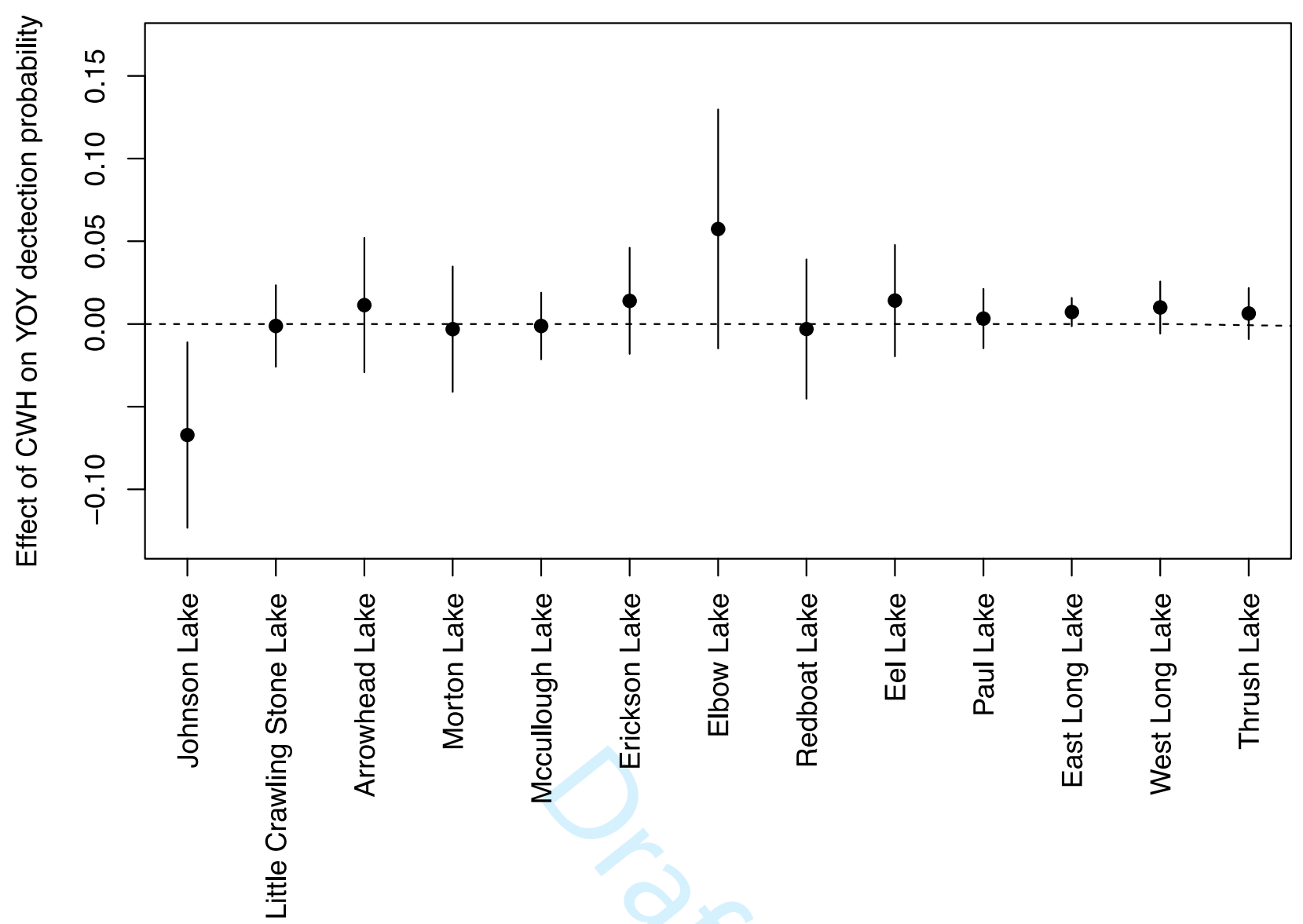

Figure 2. Detection probability of young of year (YOY) was unrelated to coarse woody habitat $(\mathrm{CWH})$ on transects in 11 of our 13 lakes. In two lakes (Johnson and West Long) there were significant effects but these were weak and in opposite directions. Note, the best model explaining West Long YOY detection probability included an effect of CWH that varied by site (two sites had significantly positive effects while the rest were not significant) but here we 390 display the lake level effect. In all lakes the best model included a constant CWH effect over time. 
391
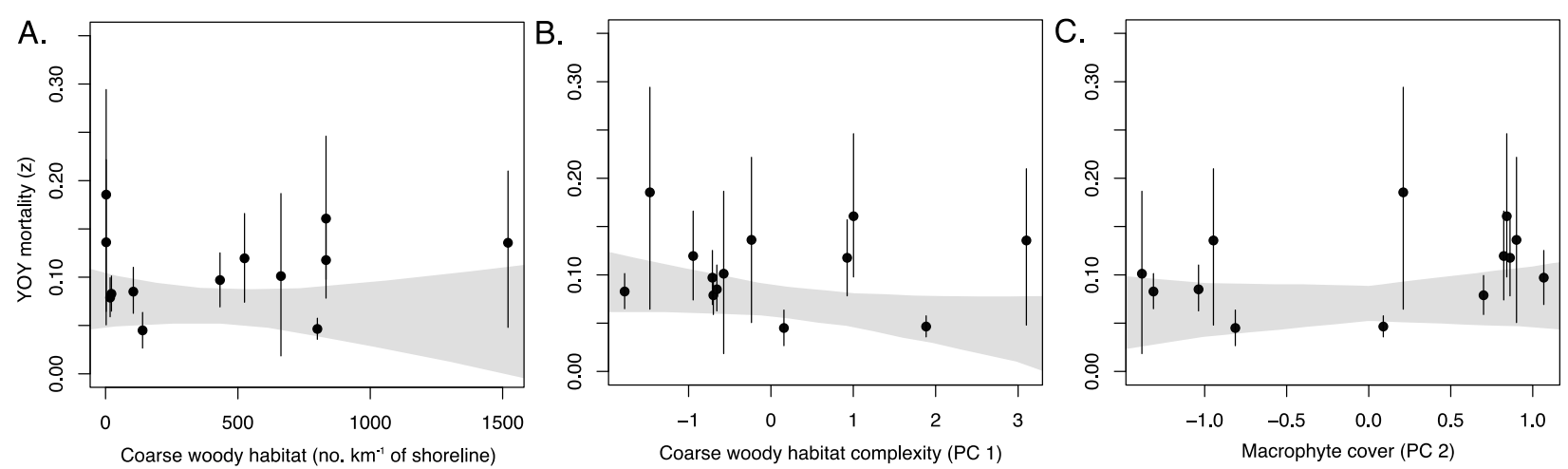

Figure 3. Young of year (YOY) largemouth bass mortality was not significantly related to coarse woody habitat density (A) coarse woody habitat complexity (B) or macrophyte cover (C). The first principal component (PC 1) from a principal component analysis describing littoral structural complexity was positively correlated to coarse woody habitat density and branchiness, while the second principal component (PC 2) was positively correlated to macrophyte cover (Table II). Models were fit with weighted least squares) regression and ordinary least squares regression. Vertical lines represent $95 \%$ confidence intervals for mortality estimate fits (z parameter in Equation 2). The shaded area is the 95\% confidence interval from a WLS regression models. 


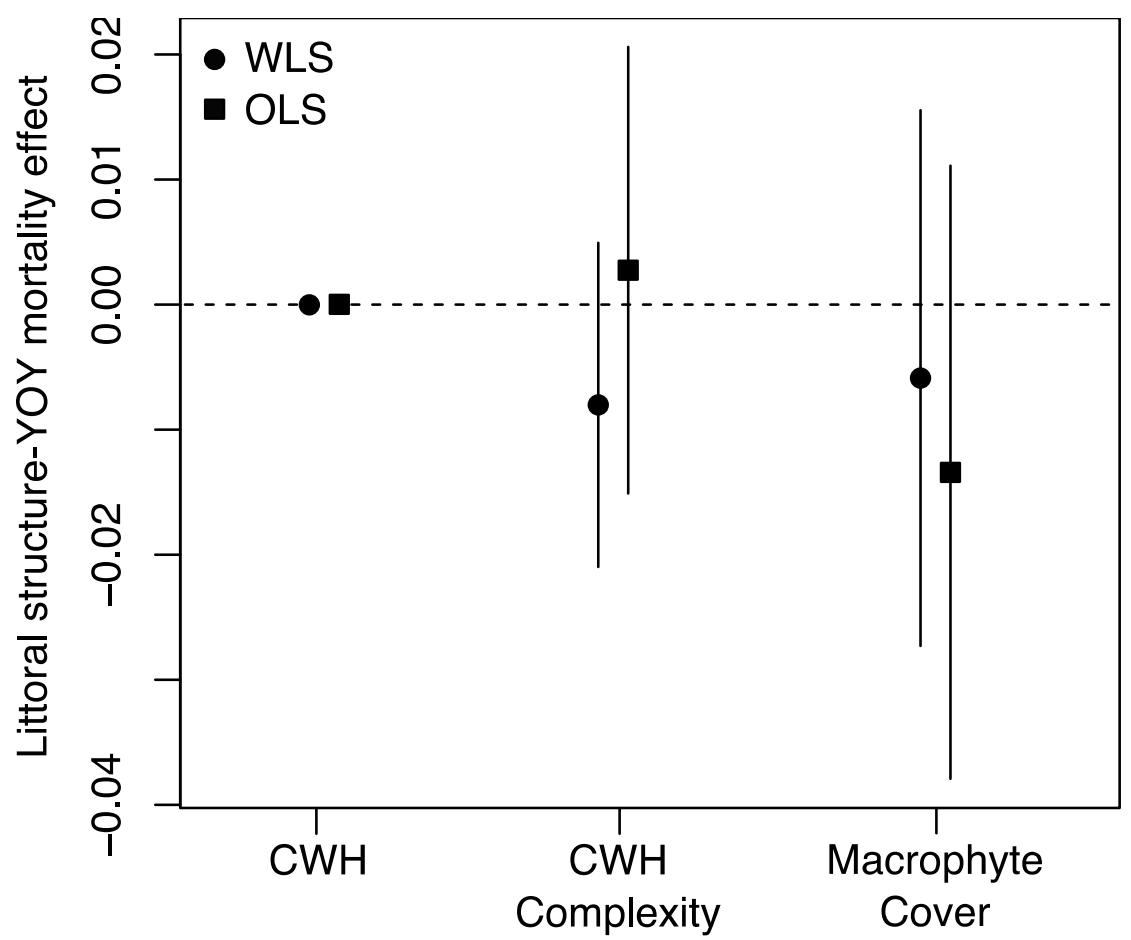

Figure 4. The effect of coarse woody habitat (CWH) on YOY mortality was near zero, while CWH complexity and macrophyte cover had more variable effects on YOY mortality but were not significantly different from zero. The effects fit with weighted least squares (WLS) regression and ordinary least squares (OLS) regression were similar. Vertical lines represent $95 \%$ confidence intervals (the lines for $\mathrm{CWH}$ are indistinguishable from the size of points). 


\section{References}

Allen, M.S., Rogers, M.W., Catalano, M.J., Gwinn, D.G., and Walsh, S.J. 2011. Evaluating the Potential for Stock Size to Limit Recruitment in Largemouth Bass. Trans. Am. Fish. Soc. 140: 1093-1100.

Anderson, J.T. 1988. A review of size-dependent survival during pre-recruit stages of fishes in relation to recruitment. J. Northwest. Atl. Fish. Sci. 55-66.

Bailey, N.T. 1990. The elements of stochastic processes with applications to the natural sciences. John Wiley \& Sons.

Ballew, N.G., Mittelbach, G.G., and Scribner, K.T. 2017. Fitness Consequences of Boldness in Juvenile and Adult Largemouth Bass. Am. Nat. 189: 396-406.

Biggs, R., Carpenter, S.R., and Brock, W.A. 2009. Turning back from the brink: Detecting an impending regime shift in time to avert it. Proc. Natl. Acad. Sci. 106: 826-831.

Bolker, B.M. 2008. Ecological models and data in R. Princeton University Press.

Brind'Amour, A., and Boisclair, D. 2004. Comparison between two sampling methods to evaluate the structure of fish communities in the littoral zone of a Laurentian lake. J. Fish Biol. 65: $1372-1384$.

Brock, W.A., and Carpenter, S.R. 2007. Panaceas and diversification of environmental policy. Proc. Natl. Acad. Sci. 104: 15206-15211.

Buckland, S.T., Anderson, D.R., Burnham, K.P., and Laake, J.L. 1993. Distance Sampling. Springer Netherlands.

Carpenter, S.R., and Brock, W.A. 2004. Spatial complexity, resilience, and policy diversity: fishing on lake-rich landscapes. Ecol. Soc. 9: 8.

Carpenter, S.R., Benson, B.J., Biggs, R., Chipman, J.W., Folley, J.A., Golding, S.A., Hammer, R.B., Hanson, P.C, Johnson, P.T.J., Kamarainen, A.M., et al. 2007. Understanding regional change: A comparison of two lake districts. BioScience 57: 323-335.

Carpenter, S.R., Brock, W.A., Hansen, G.J.A., Hansen, J.F., Hennessy, J.M., Isermann, D.A., Pedersen, E.J., Perales, K.M., Rypel, A.L., Sass, G.G., et al. 2017. Defining a safe operating space for inland recreational fisheries. Fish Fish. 18: 1150-1160.

Chamberland, J.M., Lanthier, G., and Boisclair, D. 2013. Comparison between electrofishing and snorkeling surveys to describe fish assemblages in Laurentian streams. Environ. Monit. Assess. 186: $1837-1846$.

Chatterjee, S., and Hadi, A.S. 2015. Regression analysis by example. John Wiley \& Sons. 
Christensen, D.L., Herwig, B.R., Schindler, D.E., and Carpenter, S.R. 1996. Impacts of lakeshore residential development on coarse woody debris in north temperate lakes. Ecol. Appl. 6: 11431149.

DeBoom, C.S., and Wahl, D.H. 2013. Effects of coarse woody habitat complexity on predatorprey interactions of four freshwater fish species. Trans. Am. Fish. Soc. 142: 1602-1614.

De Vos, K. 2010. Cell Counter. University of Sheffield, Academic Neurology.

Duarte, C.M., and Alcaraz, M. 1989. To produce many small or few large eggs: A sizeindependent reproductive tactic of fish. Oecologia 80: 401-404.

Eklöv, P. 1997. Effects of habitat complexity and prey abundance on the spatial and temporal distributions of perch (Perca fluviatilis) and pike (Esox lucius). Can. J. Fish. Aquat. Sci. 54: $1520-1531$.

Essig, R.J., and Cole, C.F. 1986. Methods of estimating larval fish mortality from daily increments in otoliths. Trans. Am. Fish. Soc. 115: 34-40.

Folke, C. (2016). Resilience (Republished). Ecol. Soc. 21.

Garvey, J.E., Wright, R.A., and Stein, R.A. 1998. Overwinter growth and survival of age-0 largemouth bass (Micropterus salmoides): revisiting the role of body size. Can. J. Fish. Aquat. Sci. 55: $2414-2424$.

Hall, D.J., and Werner, E.E. 1977. Seasonal distribution and abundance of fishes in the littoral zone of a Michigan lake. Trans. Am. Fish. Soc. 106: 545-555.

Hansen, G.J.A., Carpenter, S.R., Gaeta, J.W., Hennessy, J.M., and Vander Zanden, M.J. 2015. Predicting walleye recruitment as a tool for prioritizing management actions. Can. J. Fish. Aquat. Sci. 72: 661-672.

Hanushek, E.A. 1974. Efficient estimators for regressing regression coefficients. Am. Stat. 28: 66-67.

Klecka, J., and Boukal, D.S. 2014. The effect of habitat structure on prey mortality depends on predator and prey microhabitat use. Oecologia 176: 183-191.

Lewin, W.C., Okun, N., and Mehner, T. 2004. Determinants of the distribution of juvenile fish in the littoral area of a shallow lake. Freshw. Biol. 49: 410-424.

Liu, J., Dietz, T., Carpenter, S.R., Alberti, M., Folke, C., Moran, E., Pell, A.N., Deadman, P., Kratz, T., Lubchenco, J., et al. 2007. Complexity of coupled human and natural systems. Science 317: $1513-1516$. 
Ludsin, S.A., and DeVries, D.R. 1997. First-year recruitment of largemouth bass: the interdependency of early life stages. Ecol. Appl. 7: 1024-1038.

MacKenzie, D.I., Nichols, J.D., Lachman Gideon B., Droege Sam, Andrew Royle J., and Langtimm Catherine A. 2002. Estimating site occupancy rates when detection probabilities are less than one. Ecology 83: 2248-2255.

MacRae, P.S., and Jackson, D.A. 2001. The influence of smallmouth bass (Micropterus dolomieu) predation and habitat complexity on the structure of littoral zone fish assemblages. Can. J. Fish. Aquat. Sci. 58: 342-351.

Marburg, A.E., Turner, M.G., and Kratz, T.K. 2006. Natural and anthropogenic variation in coarse wood among and within lakes. J. Ecol. 94: 558-568.

Mazerolle J.M. 2017. AICcmodavg: Model selection and multimodel inference based on (Q)AIC(c). R package version 2.1-1. Available from https://cran.rproject.org/package=AICcmodavg.

Miller, T.J., Crowder, L.B., Rice, J.A., and Marschall, E.A. 1988. Larval size and recruitment mechanisms in fishes: toward a conceptual framework. Can. J. Fish. Aquat. Sci. 45: 1657-1670.

Miller, S.J., and Storck, T. 2011. Temporal Spawning Distribution of Largemouth Bass and Young-of-Year Growth, Determined from Daily Otolith Rings. Trans. Am. Fish. Soc. 113: 571578.

Miranda, L.E., and Hubbard, W.D. 1994a. Winter survival of age-0 largemouth bass relative to size, predators, and shelter. North Am. J. Fish. Manag. 14: 790-796.

Miranda, L.E., and Hubbard, W.D. 1994b. Length-dependent winter survival and lipid composition of age-0 largemouth bass in Bay Springs Reservoir, Mississippi. Trans. Am. Fish. Soc. 123: 80-87.

Miranda, L.E., and Muncy, R.J. 2011. Recruitment of Young-of-Year Largemouth Bass in Relation to Size Structure of Parental Stock. North Am. J. Fish. Manag. 7: 131-137.

Mollenhauer Robert, Logue Daniel, and Brewer Shannon K. 2018. Quantifying Seining Detection Probability for Fishes of Great Plains Sand-Bed Rivers. Trans. Am. Fish. Soc. 147: 329-341.

Mullner, S.A., Hubert, W.A., and Wesche, T.A. 1998. Snorkeling as an alternative to depletion electrofishing for estimating abundance and length-class frequencies of trout in small streams. North Am. J. Fish. Manag. 18: 947-953.

Nash K. T., Hendry K., and Cragg-Hine D. 2001. The use of brushwood bundles as fish spawning media. Fish. Manag. Ecol. 6: 349-356. 
560 Olson, M.H. 1996. Ontogenetic Niche Shifts in Largemouth Bass: Variability and Consequences 561 for First-Year Growth. Ecology 77: 179-190.

562

563

564

565

566

567

568

569

570

571

572

573

574

575

576

577

578

579

580

581

582

583

584

585

586

587

588

589

590

591

592

593

594

595

596

597

598

599

600

601

602
Parkos, J.J., and Wahl, D.H. 2002. Towards an understanding of recruitment mechanisms in largemouth bass. In Black Bass: Ecology, Conservation, and Management, D.P. Philipp, and M.S. Ridgway, eds. (Bethesda: Amer Fisheries Soc), pp. 25-45.

Pine, W.E., Ludsin, S.A., and DeVries, D.R. 2000. First-Summer Survival of Largemouth Bass Cohorts: Is Early Spawning Really Best? Trans. Am. Fish. Soc. 129: 504-513.

Persson, L., and de Roos, A.M. 2013. Symmetry breaking in ecological systems through different energy efficiencies of juveniles and adults. Ecology 94: 1487-1498.

Pink, M., Pratt, T.C., and Fox, M.G. 2007. Use of underwater visual distance sampling for estimating habitat-specific population density. North Am. J. Fish. Manag. 27: 246-255.

Post, J.R., and Evans, D.O. 1989. Size-dependent overwinter mortality of young-of-the-year yellow perch (Perca flavescens): laboratory, in situ enclosure, and field experiments. Can. J. Fish. Aquat. Sci. 46: 1958-1968.

Post, J.R., and Parkinson, E.A. 2001. Energy allocation strategy in young fish: Allometry and survival. Ecology 82: 1040-1051.

Post, D.M., Kitchell, J.F., and Hodgson, J.R. 1998. Interactions among adult demography, spawning date, growth rate, predation, overwinter mortality, and the recruitment of largemouth bass in a northern lake. Can. J. Fish. Aquat. Sci. 55: 2588-2600.

Post, J.R., Parkinson, E.A., and Johnston, N.T. 1999. Density-dependent processes in structured fish populations: interaction strengths in whole-lake experiments. Ecol. Monogr. 69: 155-175.

Pratt, T.C., and Fox, M.G. 2001. Biotic influences on habitat selection by young-of-year walleye (Stizostedion vitreum) in the demersal stage. Can. J. Fish. Aquat. Sci. 58: 1058-1069.

R Core Team 2017. R: A language and environment for statistical computing. R Foundation for Statistical Computing, Vienna, Austria. ISBN 3-900051-07-0, URL http://www.R-project.org.

Rice, J., Bradford, M.J., Clarke, K.D., Koops, M.A., Randall, R.G., and Wysocki, R. (2015). The science framework for implementing the fisheries protection provisions of Canada's Fisheries Act. Fisheries 40: 268-275.

Ricker, W.E. (1954). Stock and Recruitment. J. Fish. Res. Board Can. 11, 559-623.

Rogers, M.W., and Allen, M.S. 2009. Exploring the generality of recruitment hypotheses for largemouth bass along a latitudinal gradient of Florida lakes. Trans. Am. Fish. Soc. 138: 23-37. 
603 Roth, B.M., Kaplan, I.C., Sass, G.G., Johnson, P.T., Marburg, A.E., Yannarell, A.C., Havlicek, 604 T.D., Willis, T.V., Turner, M.G., and Carpenter, S.R. 2007. Linking terrestrial and aquatic ecosystems: The role of woody habitat in lake food webs. Ecol. Model. 203: 439-452.

Sass, G.G., Kitchell, J.F., Carpenter, S.R., Hrabik, T.R., Marburg, A.E., and Turner, M.G. $2006 a$. Fish community and food web responses to a whole-lake removal of coarse woody habitat. structural complexity and prey body morphology on fish predator-prey interactions. Ecol. Freshw. Fish 15, 301-308.

Savino, J.F., and Stein, R.A. 1982. Predator-Prey Interaction between Largemouth Bass and Bluegills as Influenced by Simulated, Submersed Vegetation. Trans. Am. Fish. Soc. 111: 255266.

Schneider, C. A., Rasband, W. S., Eliceiri, K. W. 2012. NIH Image to ImageJ: 25 years of image analysis. Nature methods 9(7): 671-675.

Schröder, A., van Leeuwen, A., and Cameron, T.C. 2014. When less is more: positive population-level effects of mortality. Trends Ecol. Evol. 29: 614-624.

Shirley, K.E., and Andrews, A.K. 1977. Growth, production, and mortality of largemouth bass during the first year of life in Lake Carl Blackwell, Oklahoma. Trans. Am. Fish. Soc. 106: 590595.

Tabor, R.A., and Wurtsbaugh, W.A. 1991. Predation risk and the importance of cover for juvenile rainbow trout in lentic systems. Trans. Am. Fish. Soc. 120: 728-738.

Turner, A.M., and Mittelbach, G.G. 1990. Predator Avoidance and Community Structure: Interactions among Piscivores, Planktivores, and Plankton. Ecology 71: 2241-2254.

Toft, J.D., Cordell, J.R., Simenstad, C.A., and Stamatiou, L.A. 2007. Fish distribution, abundance, and behavior along city shoreline types in Puget Sound. North Am. J. Fish. Manag. 27: $465-480$.

Van der Lee, A.S., and Koops, M.A. 2015. Are small fishes more sensitive to habitat loss? A generic size-based model. Can. J. Fish. Aquat. Sci. 73: 716-726.

Vélez-Espino, L.A., and Koops, M.A. 2012. Capacity for increase, compensatory reserves, and catastrophes as determinants of minimum viable population in freshwater fishes. Ecol. Model. 247: 319-326.

646

Venables, W. N., and Ripley, B. D. 2002. Modern Applied Statistics with S. Fourth Edition. Springer, New York. 
647 Wallus, R., and Simon, T.P. 2008. Reproductive biology and early life history of fishes in the 648 Ohio River drainage: Elassomatidae and Centrarchidae. CRC press.

650 Walters, C., and Kitchell, J.F. 2001. Cultivation/depensation effects on juvenile survival and 651 recruitment: implications for the theory of fishing. Can. J. Fish. Aquat. Sci. 58: 39-50.

Weidel, B.C., Josephson, D.C., and Kraft, C.E. 2007. Littoral fish community response to smallmouth bass removal from an Adirondack lake. Trans. Am. Fish. Soc. 136: 778-789.

Williams, W., and Lewis, D. 2008. Strategic management tools and public sector management.

657 Public Manag. Rev. 10: 653-671. 
665 Table I. Study lake information and young of the year mortality model estimates. 95\% confidence intervals are provided in parentheses, $666 \mathrm{YOY}=$ young of the year, $\mathrm{CWH}=$ coarse woody habitat, inst. daily mort. $=$ instantaneous daily mortality, ab. $=$ abundance, and neg. binom. $=$ 667 negative binomial. Note initial YOY abundances reported in natural log. Littoral area was calculated as shoreline perimeter $\times$ average length 668 from shore where sediment light was 1\% surface light (determined from littoral slope and Secchi depth).

\begin{tabular}{|c|c|c|c|c|c|c|c|c|c|}
\hline Lake & Year & Lat. & Long & $\begin{array}{c}\text { CWH (no. } \\
\text { km}^{-1} \text { of } \\
\text { shoreline) }\end{array}$ & $\begin{array}{l}\text { Area } \\
\left(\mathbf{k m}^{2}\right)\end{array}$ & $\begin{array}{c}\text { Littoral } \\
\text { area } \\
\left(\mathbf{k m}^{2}\right) \\
\end{array}$ & $\begin{array}{l}\text { z (YOY inst. } \\
\text { daily mort.) }\end{array}$ & $\begin{array}{c}\mathbf{X}_{0}(\ln \text { initial } \\
\text { YOY ab. })\end{array}$ & $\begin{array}{c}\text { k (Neg. Binom. } \\
\text { dispersion) }\end{array}$ \\
\hline $\begin{array}{l}\text { Johnson } \\
\text { Little } \\
\text { Crawling }\end{array}$ & 2017 & 45.90 & -89.72 & 2.5 & 0.35 & 0.21 & $0.19( \pm 0.09)$ & $3.55( \pm 1.01)$ & $0.010( \pm 0.009)$ \\
\hline Stone & 2017 & 45.92 & -89.90 & 2.5 & 0.47 & 0.34 & $0.14( \pm 0.09)$ & $3.09( \pm 3.78)$ & $0.010( \pm 0.007)$ \\
\hline Arrowhead & 2017 & 45.91 & -89.69 & 17 & 0.40 & 0.30 & $0.08( \pm 0.02)$ & $4.90( \pm 0.76)$ & $0.10( \pm 0.02)$ \\
\hline Morton & 2016 & 46.19 & -89.58 & 23 & 0.70 & 0.50 & $0.08( \pm 0.02)$ & $2.17( \pm 0.54)$ & $0.16( \pm 0.04)$ \\
\hline McCullough & 2016 & 46.20 & -89.57 & 100 & 0.93 & 0.31 & $0.09( \pm 0.03)$ & $2.63( \pm 0.56)$ & $0.05( \pm 0.02)$ \\
\hline Erickson & 2017 & 45.95 & -89.62 & 140 & 0.47 & 0.30 & $0.04( \pm 0.02)$ & $1.18( \pm 0.32)$ & $0.7( \pm 0.3)$ \\
\hline Elbow & 2017 & 46.35 & -89.78 & 430 & 0.11 & 0.14 & $0.10( \pm 0.03)$ & $4.40( \pm 0.63)$ & $0.16( \pm 0.04)$ \\
\hline Redboat & 2017 & 46.34 & -89.77 & 530 & 0.11 & 0.13 & $0.12( \pm 0.05)$ & $5.12( \pm 0.96)$ & $0.020( \pm 0.008)$ \\
\hline Eel & 2017 & 46.30 & -89.76 & 660 & 0.23 & 0.48 & $0.10( \pm 0.09)$ & $5.33( \pm 2.76)$ & $0.010( \pm 0.004)$ \\
\hline Paul & 2016 & 46.25 & -89.50 & 800 & 0.016 & 0.03 & $0.05( \pm 0.01)$ & $2.87( \pm 0.27)$ & $0.21( \pm 0.05)$ \\
\hline East Long & 2016 & 46.24 & -89.50 & 830 & 0.033 & 0.02 & $0.16( \pm 0.08)$ & $2.07( \pm 1.97)$ & $0.02( \pm 0.01)$ \\
\hline West Long & 2016 & 46.24 & -89.50 & 830 & 0.054 & 0.07 & $0.12( \pm 0.04)$ & $3.39( \pm 3.91)$ & $0.02( \pm 0.01)$ \\
\hline Thrush & 2017 & 46.32 & -89.79 & 1500 & 0.32 & 0.13 & $0.14( \pm 0.06)$ & $4.99( \pm 0.84)$ & $0.020( \pm 0.007)$ \\
\hline \multicolumn{10}{|l|}{ Range } \\
\hline & & & & $2.5-1500$ & $0.016-0.93$ & $0.7-1.8$ & $0.04-0.19$ & $1.18-5.33$ & $0.01-0.7$ \\
\hline
\end{tabular}


670 Table II. Description of littoral structure principal components. Correlations show the 671 relationship of the number of pieces of wood per $\mathrm{km}$ of shoreline, mean branchiness of coarse 672 woody, and percent macrophyte cover with two principal components from a principal 673 component analysis that explains $92 \%$ of the variation in these three variables. Significant 674 correlations are highlighted in bold.

\begin{tabular}{lll}
\hline \hline Littoral structure & PC 1 & PC 2 \\
\hline Coarse woody habitat complexity & & \\
Number per km of shoreline & $\mathbf{r}=\mathbf{0 . 9 3} \mathbf{p}<\mathbf{0 . 0 0 1}$ & $\mathrm{r}=0.10 \mathrm{p}=0.75$ \\
Mean Branchiness & $\mathbf{r}=\mathbf{0 . 8 5} \mathbf{p}<\mathbf{0 . 0 0 1}$ & $\mathrm{r}=0.40 \mathrm{p}=0.17$
\end{tabular}

Macrophyte cover

Percent cover

$$
\mathrm{r}=0.51 \mathrm{p}=0.07 \quad \mathbf{R}=\mathbf{0 . 8 5} \mathbf{p}<\mathbf{0 . 0 0 1}
$$

\section{Variance explained}

$\begin{array}{ll}0.62 & 0.30\end{array}$




\section{Figure Captions}

678 Figure 1. An example of young of year (YOY) largemouth bass counts per $10 \mathrm{~m}$ transect line 679 over study period for a single lake (see SI Fig. S2 for plots from all lakes). Individual points 680 represent total number of YOY present on a $10 \mathrm{~m}$ transect line and are jittered to prevent over 681 plotting (sampling days were $0,7,25,38$, and 49). The solid line shows the fit of the model used 682 to estimate YOY mortality (a negative exponential model with negative binomial errors). Note 683 that the y-axis is in logarithmic scale.

684

Figure 2. Detection probability of young of year (YOY) was unrelated to coarse woody habitat (CWH) on transects in 11 of our 13 lakes. In two lakes (Johnson and West Long) there were significant effects but these were weak and in opposite directions. Note, the best model explaining West Long YOY detection probability included an effect of CWH that varied by site (two sites had significantly positive effects while the rest were not significant) but here we display the lake level effect. In all lakes the best model included a constant CWH effect over time.

Figure 3. Young of year (YOY) largemouth bass mortality was not significantly related to coarse woody habitat density (A) coarse woody habitat complexity (B) or macrophyte cover (C). The first principal component (PC 1) from a principal component analysis describing littoral structural complexity was positively correlated to coarse woody habitat density and branchiness, while the second principal component (PC 2) was positively correlated to macrophyte cover (Table II). Models were fit with weighted least squares) regression and ordinary least squares regression. Vertical lines represent $95 \%$ confidence intervals for mortality estimate fits (z parameter in Equation 2). The shaded area is the $95 \%$ confidence interval from a WLS regression models.

Figure 4. The effect of coarse woody habitat (CWH) on YOY mortality was near zero, while CWH complexity and macrophyte cover had more variable effects on YOY mortality but were not significantly different from zero. The effects fit with weighted least squares (WLS) regression and ordinary least squares (OLS) regression were similar. Vertical lines represent $95 \%$ confidence intervals (the lines for CWH are indistinguishable from the size of points). 